\title{
Para perto futuro prometeu muita coisa republicana: a travessia da cultura política brasileira em Grande Sertão: Veredas ${ }^{1}$
}

\section{Bruno Flávio Lontra Fagundes}

Médico de formação, diplomata e escritor, João Guimarães Rosa certamente foi um grande renovador da literatura brasileira, consolidando em definitivo a independência literária do país dos cânones estéticos europeus. É preciso, no entanto, perceber o "escritor vaqueiro" de Cordisburgo - como ele mesmo se qualificava - no interior de uma tradição de pensamento interpretativo sobre a cultura política e a sociedade brasileira. Grande Sertão: Veredas, seu livro mais conhecido e consagrado, indica o tratamento dado a categorias caras à história do pensamento social brasileiro como raça, território, meio, trabalho, cultura e natureza. Ali, a natureza não é hostil, não há conflitos de raças, sertanejos não são pobres vítimas de desigualdades, homens sem escola e letra convivem com homens de letra e com a letra escrita, e o trabalho não é valor estruturante das lutas, sacrifícios ou conquistas humanas.

Em Grande Sertão: Veredas, personagens e acontecimentos corporificam e expressam conflitos que atravessam a formação histórica do país e que estão no centro do difícil processo de constituição de uma cultura política brasileira. O livro é fonte fecunda para o estudo das representações sobre o Brasil, propondo soluções interpretativas de exame das tensões básicas que marcam o campo político das relações de poder. Para quem o quiser ler como testemunho, o livro discorre sobre a marca do processo de institucionalização de uma comunidade política republicana no Brasil desde o pós-1889 até a modernização capitalista nos anos 1950, que é a época em que, já velho e herdeiro de terras, Riobaldo Tatarana recebe a visita do senhor que viaja pelo sertão a busca de estórias, provavelmente para escrever um livro. ${ }^{2}$ Tempo em que "(...) os costumes demudaram. Quase que, de legítimo leal, pouco sobra, nem não sobra mais nada (...)”. Pelo relato de um jagunço que carrega as contradições da história brasi- 
leira do período, a narrativa oferece valiosas balizas analíticas do que seria o específico de uma cultura política republicana brasileira. Esse trabalho identifica algumas daquelas tensões como configuradas no romance e aponta, na realidade brasileira "inventada" no livro, como indicadores de culturas políticas convivem e se conflitam traduzidas em ações e falas de personagens, como a que dá título a esse trabalho, emitida por Zé Bebelo, um dos personagens mais emblemáticos de Grande Sertão: Veredas.

Fonte histórica para o historiador, o texto de natureza ficcional se justifica. Qualquer organização de dados num relato que comunica uma realidade não escapa dos processos de linguagem criadores de significado, porém nem tudo que deriva dele é absolutamente opaco a ponto de não podermos afirmar realidade alguma a partir dos textos literários. Hayden White e Wolfgang Iser já alertaram da medida de realidade que envolve os dispositivos representacionais em Literatura. Ao afirmar que o conhecimento historiográfico não diminui porque os historiadores conferem sentido a suas narrativas da mesma maneira que escritores de ficção, White alega que, assim só o seria se "acreditássemos que a literatura não nos ensinou algo acerca da realidade, por ter sido o produto de uma imaginação que não era deste mundo, mas de outro, de um mundo inumano (...)" (White, 2001:115). Já Iser adverte-nos de que nem tudo no texto ficcional é fictício, visto que "há no texto ficcional muita realidade que não só deve ser identificável como realidade social, mas que também pode ser de ordem sentimental e emocional" (Iser, 1996:14). A análise de literatura com ênfase no político não significa destacar o acontecimento literário da trama do texto e reduzi-lo à condição de reflexo da realidade concreta extratextual. Estratégias e arranjos do universo das relações de poder podem ser observados pelo modo como a literatura representa ficcionalmente a realidade vivida; ao representar a realidade no texto, o ardil literário fornece esquemas persuasivos de interpretação dos processos sociais como construídos no discurso ficcional, de modo a sugerir o conjunto de percepçôes e valorações de que lançam mão os agentes reais da vida política apreendidos na figura dos personagens fictícios da vida ficcionada do texto. Os diversos acontecimentos relatados em Grande Sertão: Veredas realizam uma representação do Brasil como uma grande travessia do arcaico ao moderno, e indicam que outras travessias talvez tivessem sido possíveis. 
Na história do Brasil, o processo de republicanização se subjuga ao peso da poderosa herança localista que marca as relações de poder. Se a república brasileira tem 1889 e 1891 como marcos temporais oficiais, nem por isso as estruturas políticas se fizeram acompanhar de formatos institucionais adequados ao convívio de práticas republicanas: a alternância de poder era instituto manietado, o sufrágio excluía a maior parte da população, e algumas cidades, que no final do século XIX começam a receber contingentes humanos consideráveis e adquirir peso político sem precedentes, viam o poder das decisões políticas deslocado para os distantes municípios longe do alcance da lei e próximo das arbitrariedades pessoais. $\mathrm{O}$ relato de Riobaldo Tatarana desnuda as ambigüidades que revelam o conflito entre uma realidade institucional de fato, incorporada ao sistema político brasileiro, e outra realidade não-instituída, que vive nos interstícios do sistema político e que aparece sob a forma de realidade possível.

É em torno dos eixos amor e guerra e sertão e cidade que se estrutura Grande Sertão: Veredas. O amor - entre Riobaldo e Diadorim - e a guerra - entre chefias locais e governo central são os vetores narrativos em torno dos quais Riobaldo conta uma mescla de sua história de vida e de história brasileira a um senhor de quem inveja a "alta instrução" e cujas idéias instruídas lhe "fornecem paz". O testemunho do velho jagunço Tatarana é o relato de alguém que admite que seu tempo já passou, onde jagunços valentões não existem mais, vaqueiro agora é "feio e capiau" e aconselha ao senhor "viagem mais dilatada" para colher "uma safra razoável de bizarrices”. Quando vai a Sete Lagoas consultar médico, Riobaldo se veste de jeito à "não me sombrearem com jagunço antigo" (17). ${ }^{3}$ Ele está mesmo no meio de uma travessia que ele representa para contar a história da passagem de um Brasil arcaico para um Brasil em que "o governo está mandando abrir boa estrada rodageira de Pirapora a Paracatu, por aí...” (24), e, como todo personagem denso e ambivalente, encarna os dilemas e as ambigüidades de toda época de transição. Grande Sertão: Veredas pode ser lido assim: Riobaldo contém nele mesmo a travessia que narra do Brasil, e a riqueza de seu relato está no fato de que ele é uma síntese de elementos persistentes de tempos passados com elementos projetados de um tempo futuro. Vamos ver especialmente o processo de inserção de Riobaldo no mundo dos jagunços, para enfatizar um dos aspectos mais salientes 
da matriz universalista da cultura política republicana: a ênfase na função socializadora da escola e de seus agentes na difusão da razão científica que prepara o homem novo para o convívio em condiçóes de igualdade numa comunidade política. As ambivalências e limitaçôes dessa função socializadora da escola na realidade da formação histórica brasileira estão magnificamente expressas nas dúvidas existenciais que atordoaram Riobaldo ao longo de sua vida de jagunço e que o continuam atordoando enquanto presta seu testemunho de homem do sertão brasileiro que ele sabe que já não há.

Terceiro ou quarto dia, que lá fui, apareceu mais gente. Dois ou três homens de fora, comprando alqueires de arroz. Cada saco amarrado com broto de buriti, a folha nova - verde a amarela, pelo comprido, meio a meio. Arcavam com aqueles sacos, e passavam, nas canoas, para o outro lado do de-Janeiro. Lá era, como ainda hoje é, mata alta. Mas, por entre as árvores, se podia ver um carro-de-bois parado, os bois que mastigavam com escassa baba, indicando vinda de grandes distâncias. Daí, o senhor veja: tanto trabalho, ainda, por causa de uns metros de água mansinha, só por falta de uma ponte. Ao que, mais, no carro-de-bois, levam muitos dias, para vencer o que em horas o senhor em seu jipe resolve. Até hoje é assim, no borco. (80)

\section{Um jagunço letrado entre jagunços sem letra. O itinerário de uma inserção}

Os acontecimentos e personagens do processo que transforma o menino Riobaldo em jagunço são expressivos dos dilemas da história sociopolítica brasileira e permitem matizar as contradições e obstáculos da constituição de uma cultura política republicana no Brasil percebida como cultura política nacional.

Com "treze ou quatorze anos", depois de curar de uma doença, Riobaldo passa a ir todo dia ao porto buscar esmolas para sua mãe pagar promessa que fizera pela cura do filho. Um dia, Diadorim tinha ido acompanhar o tio na venda de umas sacas de arroz, Riobaldo o conhece e com ele faz a travessia do rio São Francisco. Ao final da travessia, os meninos se despedem sem saber se se encontrariam de novo um dia, mas o menino Riobaldo não esconde o encantamento do primeiro momento. Passado o tempo, morrendo sua mãe, ele é levado por uma vizinha para a Fazenda São Gregório, do 
tio e padrinho Selorico Mendes. Entre estórias de "altas artes de jagunços" que ouvia o tio contar e com as quais "ele sempre se engrandecia" (88), um dia o padrinho lhe mostra um recibo de compra de pólvora que guardava como lembrança de um jagunço que conhecera, mas Riobaldo não sabe ler. O padrinho toma a decisão, então, de enviá-lo para a casa de Nhô Maroto, no Curralinho, aonde ia "para ter escola" na escola de Mestre Lucas.

Se seguirmos Berstein, Selorico Mendes manifesta o princípio da cultura política republicana que concebe o indivíduo como alguém dotado da razão e livre de superstição para viver num mundo onde o progresso está fundado sobre o poder da ciência. O sobrinho Riobaldo precisa do conhecimento e do saber que a escola lhe fornece se quiser ter alguma chance na vida pública que o aguarda, e o padrinho entende isso. Mesmo mergulhado num universo de memória e conhecimento que se transmitem pelas palavras que vão de boca a boca, Selorico sabe que é importante o sobrinho se formar para um universo em que é crucial o domínio dos saberes que a escola transmite pela escrita e pela leitura. A letra escrita e lida que a escola ensina favorece o registro e a transmissão da memória em papéis e livros, e isso Riobaldo provavelmente aprendeu: naqueles tempos novos, sua história tem mais chances de permanecer se fixada no livro do senhor que o entrevista para escrever uma história do sertão modificado pelo processo de modernização. No Curralinho, a vida de Riobaldo the prepara para alternativas à vida de jagunço. Maroto lhe diz, certo dia, que ele não era habilidoso para coisas triviais e "carecia mesmo [é] de estudar e tirar carta-de-doutor" (89). Impressionado, Riobaldo vai dizer aquilo a Mestre Lucas, que lhe confirma: "É certo. Mas o mais certo de tudo é que um professor de mão cheia você dava...” No segundo ano de instrução, Riobaldo já ensinava aos meninos menores "as letras e a tabuada" (89).

Estudado e instruído, de volta à fazenda do padrinho, certa noite Riobaldo presencia uma cena que é o primeiro passo em direção ao mundo dos jagunços. Dois fazendeiros, Alarico e Aluiz Totõe, acompanhados de Joca Ramiro e seus homens, vão pedir a Selorico esconderijo para os jagunços que passavam naquela noite ali perto "por uma questão política”. Riobaldo vê, na penumbra da sala, a figura legendária de Ramiro e de seus principais jagunços, e é ele quem os conduz na noite ao lugar onde deviam dormir. Era a vida de jagunço que começava a se conceber para 
Riobaldo. Remanescente de um mundo de homens gloriosos e dignos de uma tradição que se perpetua no livro que o senhor vai escrever, Riobaldo sabe que seu relato valoriza o passado e institui a posteridade daqueles homens com os quais ele constituiu uma comunidade política de crenças, hábitos e valores. E como todo passado precisa de uma baliza fundadora, pode-se dizer que Riobaldo funda no encontro com Ramiro na calada da noite a baliza que institui o momento primeiro de sua inscrição naquele mundo de tradições gloriosas. Brincando um pouco com as palavras, podemos dizer que o encontro com Joca Ramiro é o acontecimento que marca o momento que lança a pedra de fundação da história de Riobaldo. Nada mais republicano, mesmo em se tratando do específico processo de republicanizacão brasileira que não institui uma comunidade de iguais tal qual a que Berstein postula quanto à matriz universalista da cultura política republicana francesa.

Indo o tempo, Riobaldo resolve fugir da fazenda do tio tocado de vergonha e desonra porque lhe haviam dito que suas feições pareciam as do padrinho: "Que ele tinha sido meu pai!", diz. No Curralinho outra vez, conta para Mestre Lucas uma mentira persuasiva: o tio lhe teria dado licença para começar ali vida própria "a fito de desenvolver mais estudos e apuramento só de cidade” (98). E eis que mais um novo fato aguarda por Riobaldo e o encaminha mais para a vida de jagunço. Na fazenda Nhanva, um fazendeiro de boa situação estava encomendando, com "garantia boa paga”, serviço de um professor, e queria que Mestre Lucas deixasse o Curralinho e sua escola por uns tempos para servi-lo. Mestre Lucas não pode e sabe que Riobaldo é seu substituto natural, tendo chegado na hora certa:

O senhor acha que eu posso? - perguntei; para principiar qualquer tarefa, quase que eu sozinho nunca tive coragem. - "Ei, pode!" - o Mestre Lucas declarou. Já que estava acondicionando numa bruaca os livros todos - geografia, aritmética, cartilha e gramática - e borracha, lápis, régua, tinteiro, tudo o que pudesse ter serventia. Aceitei (...) (99).

Riobaldo chega então à fazenda Nhanva, e o fazendeiro que precisa de seus serviços é Zé Bebelo, que estava preparando homens para "relimpar o mundo da jagunçada braba” (101). Inquieto, inteligente de reter rápido o ler e o escrever, leitor contumaz de jornais, logo logo Bebelo contro- 
la as quatro operaçôes e aprende as matérias. Depois que "estável, abolisse o jaguncismo (...)” (102) projetava virar político, e todos já lhe antecipavam alcunha: "Deputado." Terminados os estudos, elogia as aulas de Riobaldo, gratifica-lhe, mas estipula: "Siô Baldo, já tomei os altos de tudo! Mas carece de você não ir s'embora não, mas antes prosseguir sendo meu secretário!” (102) Riobaldo se torna, então, seu secretário, aquele quem vai historiar as façanhas de Bebelo. Se, conforme Berstein, sabemos que a cultura política republicana se constitui na base dos "acontecimentos verdadeiramente fundadores" e vive da reatualização periódica de seus heróis gloriosos e suas datas sagradas, Bebelo manifesta essa consciência. Ele sabe que seu futuro político de "muita coisa republicana" não pode prescindir dos acontecimentos de um Brasil que acredita estar fundando e para cujos registros convoca Riobaldo, que domina a escrita que vai fixar no papel os feitos do homem que "quer limpar o Norte dos jagunços" e passar para a história como aquele que mudou o sertão. Na tarefa de secretário das batalhas de Zé Bebelo, Riobaldo dá mais um passo para o mundo dos jagunços sertanejos. Agora ele acompanha as batalhas e ali desenvolve o que o distinguirá de todos os demais homens: a prerrogativa da letra escrita, aprendida e chancelada pela escola de Mestre Lucas! Essa prerrogativa ajuda a plantar em Riobaldo a dúvida existencial humanista entre os que sabem a letra, aprendida por ele, e os que não sabem a letra, o universo do qual provém. Dúvida entre os homens instruídos, que Riobaldo tem apenas pela metade, e os homens sertanejos, analfabetos, como João Goanhá, "pessoa muito leal e briosa"

Na primeira batalha em que venceu, Zé Bebelo manda Riobaldo esperar até que "os municipais do lugar" se reúnam para ele fazer discurso e que um estafeta venha registrar a história da vitória. Não veio o estafeta, e foi Bebelo mesmo quem dispôs "uma tábua por cima de um canto de cerca" e discursou, elogiando a lei e dando vivas ao governo. Depois era Riobaldo quem devia fazer discurso em nome dele: "falar muita coisa nacional" era o que Bebelo lhe mandava. Indo o tempo, Riobaldo enjoa do serviço de secretário que anota e escreve façanhas, e foge outra vez, tal como o fizera da fazenda do tio. Ele agora passa a vagar pelo sertão, já envolvido na dúvida entre ser ou não ser jagunço num sistema político de lutas entre coronéis, fazendeiros e chefes locais. 
Fugi. De repente, eu vi que não podia mais, me governou um desgosto. Não sei se era porque eu reprovava aquilo: de se ir, com tanta maioria e largueza, matando e prendendo gente, na constante brutalidade. Debelei que descuidassem de mim, restei escondido retardado. Vim-me. (105)

Solto e sozinho, Riobaldo volta a vagar pelo sertão. Na barra do Córrego Batistério, ele dorme com uma mulher que lhe indica ir até a casa de seu pai, onde terá pouso e comida. Acolhido na casa de Malinácio, lá ele inventa estórias de si, se engrandecendo, contando que estava passando por ali indo para o Norte se juntar ao bando de Joca Ramiro. Almond e Verba admitem que, em qualquer sociedade, a relação entre sujeitos e estruturas sociais é mediada por um conjunto de orientaçôes psicológicas: os indivíduos se orientam por sentimentos, crenças e valores internalizados com relação às instituições sociais, que não bastam por si mesmas para fazer os homens como são. Para os autores, as sociedades que têm melhor desempenho institucional combinam balanceadamente aquelas orientações de forma que o indivíduo se sinta parte de uma comunidade de pertencimento sem que suas atitudes e vontades individuais sejam esmagadas por ela. Assim podemos interpretar o que se passa com Riobaldo ao contar suas estórias a Malinácio: hesitante entre a individualidade de que não admite abrir mão e atraído por uma comunidade de jagunços regrada por normas que deve observar, Riobaldo está a procura de sua identidade de pertencimento. As estórias que conta para Malinácio são como a estratégica referência a estórias que lhe atribuem a fama imperecível que advém do repertório de estórias de homens gloriosos como Joca Ramiro. A cultura política republicana precisa demarcar o início da história pela mão de alguns heróis fundadores, e Riobaldo encarna um combinado de culturas políticas: a de bandos de jagunços para os quais a própria vida vai tratando de socializar desde a infância - uma cultura tradicional - e a de homens instruídos que se socializam pela escola que o prepara para a civitas - uma cultura republicana, permanentemente incompleta no interior da específica história da republicanização brasileira.

Indivíduo que se revolta com as normas e regras sociais ao abandonar a gente de Zé Bebelo, falta ainda a Riobaldo o acontecimento que o ligará de vez aos bandos de jagunços que povoam o sertão. Naquele fim de tarde, depois de dormir, Riobaldo acorda com a presença na sala de três 
homens que conversam com Malinácio. São jagunços de Joca Ramiro. Malinácio contara a eles o que ouvira de Riobaldo, que logo é indagado porque não tinha ido direto para o Norte encontrar com os homens de Ramiro. Confirmando que aquela era sua intenção, Riobaldo sai do embaraço dizendo que preferira dar uma "volta cautelosa" primeiro; ter calma para "resolver os projetos em meu espírito", responde. Depois de alguma conversa desconfiada entre aqueles homens, ocorre o fato imprevisível que vai conduzir Riobaldo de vez para o mundo dos jagunços: enquanto conversavam na sala, "mais um homem, tropeiro também, vinha entrando, na soleira da porta”. Era o Menino, o da travessia do São Francisco, com quem estava se reencontrando.

Reinaldo - como ele se chamava. Era o Menino do Porto, já expliquei. E desde que ele apareceu, moço e igual, no portal da porta, eu não podia mais, por meu próprio querer, ir me separar da companhia dele, por lei nenhuma: podia? (108-109)

O que era dúvida e só existira na palavra, vai deixar de ser para se tornar realidade: agora Riobaldo vai virar jagunço! Se a forte emoção de reencontrar novamente o Menino daquela travessia, agora para sempre, é o que Riobaldo confessa como motivo que o atrai de vez para a vida de jagunço, é preciso não desprezar o fato de que ele é um sertanejo pobre e disponível para ser recrutado pelas lutas políticas intestinas que marcam a difícil consolidação da vida republicana na história brasileira. O sentimento por Diadorim, que no romance acontece ao acaso de andanças de homens sertanejos pelo sertão, não existe no vácuo: ele se enlaça a uma escolha que Riobaldo faz por uma cultura política entre outras. Se, para ele, a associação com o tio fazendeiro, a participação em negócios comerciais de gente que conhece pelo sertão ou mesmo fazer serviços de secretário ou professor com os meios que a escola lhe forneceu são escolhas possíveis, nem por isso ele as escolhe. Aquele ambiente de homens iletrados, analfabetos e rústicos faz parte de seu horizonte de expectativas também, e ele escolhe o caminho do sistema político mais tradicional. É preciso não pararmos na escolha de Riobaldo apenas como uma escolha sentimental por Diadorim, belíssima solução para o roteiro do romance. Há mais nessa escolha, e aqui pleiteamos que a solução que o romance confere ao personagem o transforma mais ainda num emblema, o emblema do desafio 
brasileiro permanente de constituir uma nação com suas referências de identidade próprias. Riobaldo é uma pessoa letrada que viveu o fracasso que, na história republicana brasileira, marcou as iniciativas governamentais de oferta de ensino público e universal, ainda mais em se tratando de ensino voltado para o homem do campo. É este caldo de cultura que Zé Bebelo quer limpar do sertão a que Riobaldo vai se juntar.

Newton Bignoto atribui aos republicanos franceses a formulação de "um conjunto de valores que servem para nossas vidas na cidade" (Bignotto, 2000:62) conectado ao equacionamento da igualdade cívica pela via da educação. No entanto, tendo em vista a atual voga de retorno ao republicanismo e a consolidação de traços de experiências democráticas contemporâneas, Bignoto adverte sobre algumas críticas possíveis ao atual idealismo republicanista. Para ele, "a idéia de que a educação seria o grande motor para se atingir a igualdade de condiçóes nas sociedades se mostrou exagerada" (Bignotto, 2000:66), e isso mesmo em experiências democráticas cheias de impasse como a experiência brasileira. É por esse viés que devemos observar Riobaldo e Selorico Mendes. Se a educação não prepara Riobaldo para uma vida entre iguais, não é só porque a história brasileira lhe fecha estruturalmente os caminhos da igualdade, mas também porque seu tio acreditava no princípio republicano de que a educação funda a igualdade entre os homens. Só depois a história vai mostrar que esse princípio se mostrou uma meia-verdade. Meia-verdade ou não, o fato é que na história brasileira, e provavelmente no tempo em que viveram Riobaldo e seu padrinho, a educação fazia os homens instruídos com mais chances de serem iguais a outros. E era essa, provavelmente, a convicção de Selorico Mendes.

\section{Cultura política republicana do Brasil e o livro que Riobaldo não escreveu}

Mas se a escolha de Riobaldo é pelo tradicional, ela contém ambivalências que adensam sua personalidade e fazem magnífico o livro, porque Grande Sertão: Veredas pode ser lido como um grande conflito político - o da difícil constituição de uma cultura política republicana no Brasil. Bem esquematicamente, poderíamos identificar os pólos desse conflito: 
os bandos de jagunços e seus chefes são uma cultura política hierárquica profundamente estratificada, onde o poder político e econômico provém da posse muitas vezes violenta da terra; Zé Bebelo encarna a oportunidade de fazer "muita coisa republicana", cujo poder ainda deriva da condição de fazendeiro e de suas relações oportunistas com o governo de que lança mão para facilitar ser eleito deputado; e Riobaldo combina elementos de uma cultura política hierárquica e estratificada com elementos de uma cultura em que, niveladas e iguais, as relações entre os homens podem ser mediadas por instituições. Até para decidir sobre assuntos que não são da política, Riobaldo reconhece eventualmente as instituições: quer que o governo convoque assembléias para decretar que o diabo não existe.

Sentado numa cadeira de balanço, contando estórias de homens gloriosos e valentes para um senhor instruído da cidade que anda pelo sertão recolhendo o que ficou de um mundo e de uma paisagem que se modificam pelo avanço da modernização capitalista, Riobaldo estrutura sua narrativa tendo em vista afirmar seu amor e rejeitar sua culpa pela morte de Diadorim. Mas há mais em seu relato: é um testemunho, num dado momento de modernização do Brasil, sobre as dificuldades de formação de uma cultura política nacional, dividida entre fraturas político-territoriais de poder e limitada pela débil reserva de legitimidade do Estado brasileiro para fazer instituir um povo político de história e tradições. Essas dificuldades atravessam Riobaldo e sua narrativa sobre o Brasil. Num certo sentido, o diabo que o atormenta é a metáfora de um país carente de proteçōes do céu, onde "até Deus quando vier que venha armado".

Zé Bebelo é, no romance, quem talvez melhor sintetize a vontade de cultura política republicana e os traços de herança política anti-republicana legados do passado histórico brasileiro. Ele é um justo: não consente "covardias de perversidade" contra prisioneiros de batalhas, que não podem ser sacrificados e devem ser encaminhados para a cadeia, onde terão o devido tratamento legal que as instituiçóes entendam dar. Informado pelo ideal do legítimo direito de defesa a todo acusado, ao mesmo tempo em que pelo sentimento de lealdade e honra que o liga a chefias personalistas, Bebelo incorpora o ideal do justo num sentido muito particular. Exige julgamento quando é capturado pelos homens de Joca Ramiro, e dele sai inocentado com a condição de só voltar ao sertão quando Rami- 
ro morresse: e é assim que o faz, ao voltar de Goiás para vingar a morte de Ramiro, o homem que lhe salvara a vida ao lhe dar julgamento e direito de defesa. Onde chegava, Bebelo gritava "vivalei, vivalei" e ao retornar para liderar os jagunços no combate aos "Hermógenes" diz "Venho do Brasil" quando perguntado de onde estava vindo.

Com Zé Bebelo, Riobaldo é um homem da letra, um secretário que anota e escreve e não um jagunço. Quando quer serviço de professor, Bebelo incorpora, talvez, mais um traço da específica cultura política republicana do Brasil que tem origem no processo de republicanização brasileira: ao mesmo tempo oportunista, em proveito próprio para facilitar seu acesso ao mundo oficial da política, a escola que ele solicita na figura de Riobaldo é a demanda republicana por uma educação que socializa e forma um povo para um convívio de nação cujos fundamentos numa história comum é o lastro de identidade e de pertencimento. $\mathrm{O}$ que garante que a escola - ou um certo tipo de escola, bem entendido - é o ideal agente formador do homem para a vida numa comunidade cívica? Ao estudar a relação entre civismo e variável escolarização no desempenho dos governos regionais italianos, Putnam constata que "historicamente, a educação deve ter cumprido importante papel no fortalecimento dos alicerces da comunidade cívica, mas hoje parece que não tem influência direta no desempenho governamental" (Putnam, 1996:131).

Através de um reformador do sertão que quer colocar ordem de governo e mudar a história do país, Riobaldo entra para a vida de jagunço com instrução e escola. Um jagunço instruído e letrado que vai se imiscuir em meio a um mundo de jagunços sem letra, o que lhe será motivo de profundas tensões, já que é um mundo em que Riobaldo ao mesmo tempo está e não está. Ele é constantemente dividido entre a herança de uma cultura política de homens pobres, destituídos da letra e sujeitos a relaçóes de poder e de mando - e uma outra cultura política aprendida, escolarizada e letrada, que lhe dá a expectativa de lançar mão dela se quiser sair daquele mundo de jagunços. A uma e outra Riobaldo ora recusa, ora se filia. Ele está mesmo numa travessia, num meio de caminho.

A narrativa de Riobaldo contém as ambivalências de um homem dividido que representa, em si mesmo, divisões e conflitos da história brasileira. A república de 1889 não consegue deitar raízes duradouras, nem criar 
uma comunidade de cidadãos que se identifique nela, e Riobaldo termina jagunço tanto pelo amor que nutre por uma mulher quanto pelo pouco estímulo que as instituições republicanas brasileiras, simbolizadas marcadamente pela escola de Mestre Lucas, não lhe conseguem incutir. A narrativa de Grande Sertão: Veredas contém um paradoxo: se de algum modo expõe a incapacidade do projeto político republicano deitar raízes no Brasil, expõe também a existência na sociedade brasileira de orientações e sensibilidades republicanas disponíveis a se entender sobre outras formas de convívio público. A narrativa de Riobaldo não seria reveladora se fosse de outro modo. Ele mesmo tem uma sensibilidade republicana: sabe que vive num tempo de progresso e de modernização que não recusa e que todo "povo" deve ter uma história fundadora, a qual ele não escreve, e para a qual presta seu relato de um tempo passado do país do qual ele é um dos poucos remanescentes.

Homem pobre, dividido entre as oportunidades que a instrução lhe promove e o recrutamento pelo jaguncismo espalhado pelo sertão, onde terá morada e comida, Riobaldo encarna os dilemas de um país. Sua angústia e dramas íntimos são metáfora dos obstáculos do percurso histórico brasileiro para se tornar república: suplantar a longa herança de jaguncismo que permeia as relações entre poder central e local e formar um povo que se apossa de um patrimônio de conhecimento universal comum transmitido pela leitura e escrita que a escola ensina. As ambigüidades de Riobaldo e as tensões que vive entre os jagunços sem letra manifestam o fato de que existem outros conteúdos explicativos do mundo que não são transmitidos pela escola universalizante e socializadora. No Grande Sertão: Veredas, os homens sem letra têm língua e cultura: lá estão suas falas, seus modos de dizer e ser. E há espécies de "índices de escola” que representam o convívio, ora tenso, ora pacífico, entre saberes que ela organiza e saberes que estão dispersos fora dela. Riobaldo estranha muitas vezes aqueles homens jagunços como ignorantes, e certamente esse é um filtro social que a escola lhe ensinou, mas uma carta sua para uma de suas mulheres no sertão circula durante anos nas mãos de jagunços sem ser aberta, indicando que os homens sem letra podem conviver com a letra escrita sem tripudiá-la.

Riobaldo está mesmo numa travessia: a suma doutoração que inveja no senhor não se compensa pelo fato de ser o "Professor", como lhe chama Zé Bebelo, e tudo o que a escola de Mestre Lucas lhe ensinou, não 
lhe ensinou o bastante para sair do sertão. E aqui vem o paradoxo que assemelha Riobaldo, talvez ao senhor que escreve o livro, e talvez mesmo a João Guimarães Rosa: se ao velho jagunço letrado lhe falta alguma coisa para escrever, ele mesmo, a história do Brasil que viveu, o senhor que a escreve não teria como fazê-lo se não contasse com Riobaldo. A escola lhe adiantou de muito e de nada: ela lhe confere alguma distinção depois de sair da jagunçagem, mas não lhe faz sair do sertão! O livro que o senhor escreve não pode prescindir de Riobaldo para contar a história de um país que se transforma, e a história do país também não pode prescindir do livro sem a qual ficaria sem o registro de sua transformação: este é um paradoxo que o livro organiza em torno da figura ambivalente de Riobaldo, e em torno da figura ambivalente do "senhor que escreve o livro": se ele é ou não o escritor João Guimarães Rosa, recolhendo estórias no sertão para colocá-las em livro, talvez ele o seja apenas metaforicamente. Como convém à literatura! A história do país ensejou ações de preservação do que se acreditava em vias de desaparecer destruído pela descaracterização do processo de modernização do Brasil. Grande Sertão: Veredas talvez seja o recurso ardiloso com que Rosa, encarnado no personagem do "senhor que escreve o livro", inscreve-se no panteão que consagra o sertão mineiro pela via da consagração de sua grande obra literária.

É sedutor pensar que há no livro uma representação do Brasil cuja modernização não precisa destruir o que seriam suas culturas legítimas, sugerindo um imaginário descrente de que a escola é central na criação de uma comunidade política nova. Paradoxo fundamental do que seria um outro projeto republicano para o Brasil e que o Grande Sertão: Veredas póe em jogo: se a escola não é central para formar uma comunidade, ela também não se funda sem o livro que a escreve com a letra que, especialmente, é a escola que ensina! Esse e tantos outros aspectos da história brasileira Riobaldo corporifica, sugerindo que o projeto republicano brasileiro poderia ter encontrado outras soluções que não estão presentes totalmente nos termos de uma tradição republicana universalista. 
Para perto Futuro prometeu muita coisa republicana: a travessia da cultura política brasileira em Grande Sertão: Veredas • 151

\section{Notas}

${ }^{1}$ Este artigo é versão modificada de trabalho final da disciplina Culturas Políticas na História: estudos de caso, realizado no segundo semestre de 2006 junto ao Programa de Pós-Graduação em História, Doutorado, da UFMG, onde, como bolsista, conto com o apoio institucional da Fundação de Amparo à Pesquisa de Minas Gerais (Fapemig).

${ }^{2}$ Neste trabalho, será feita referência a esse personagem do livro apenas como "senhor". ${ }^{3}$ Trabalho com a $5^{\text {a }}$ edição de Grande Sertão: Veredas, de 1967. Os números entre parênteses assinalam o número da página da qual o trecho foi retirado. Alguns pequenos pedaços foram retirados apenas para compor esse texto e nem foram localizadas as páginas.

\section{Referências bibliográficas}

ALMOND, G.A; VERBA, S. The civic culture political attitudes and democracy in five nations. Estados Unidos: Little, Brown and Company, 1963.

BERSTEIN, Serge. Le modèle républicain: une culture politique syncrétique. In: 1999, p. 113-143.

(Org.). Les cultures politiques em France. Paris: Éditions du Seuil,

. A cultura política. In: RIOUX; SIRINELLI (Orgs.). Para uma história cultural. Lisboa: Estampa, 1998, p. 349-363.

BIGNOTTO, Newton. Humanismo cívico hoje. In: (Org.). Pensar a República. BHTE: Editora da UFMG, 2000, p. 49-70.

CARDOSO, Sérgio. Por que República? Notas sobre o ideário democrático e republicano. In: (Org.). Retorno ao republicanismo. BHTE: Editora UFMG, 2004, p. 45-66.

CARVALHO, José Murilo. Os bestializados. O Rio de Janeiro e a República que não foi. 3a ed. São Paulo: Companhia das Letras, 1987.

ISER, Wofgang. Atos de fingir. In: . O fictício e o imaginário: perspectivas de uma antropologia literária. Rio de Janeiro: EdUERJ, 1996, p. 13-37.

PUTNAM, Robert D. Comunidade e democracia a experiência da Itália moderna. Rio de Janeiro: Fundação Getúlio Vargas, 1996.

ROSA, João Guimarães. Grande Sertão: Veredas. 5aㅡ ed. Rio de Janeiro: José Olympio Editora, 1967.

WHITE, Hayden. O texto histórico como artefato literário. In: . Trópicos do discurso. Ensaios sobre a crítica da cultura. São Paulo: Edusp, 2001, p. 97-116. 


\section{RESUMO}

$O$ artigo identifica algumas tensōes e ambigüidades presentes na narrativa de Grande Sertão: Veredas, de João Guimarães Rosa. Analisa o processo de inserçãa do protagonista Riobaldo Tatarana no mundo de jagunços sertanejos, verificando como o personagem corporifica alguns dilemas cruciais da constituição de uma cultura politica republicana no Brasil, especialmente quanto às contradiçôes do papel da escola na formação de uma comunidade cívica brasileira de memória e tradições. Mais, esse artigo postula que Riobaldo Tatarana encarna na narrativa um dos maiores conflitos na constituição de uma cultura política republicana brasileira durante o século $X X$, aquele do relacionamento entre cultura letrada e o analfabetismo.

Palavras-chave: Cultura politica, republicanismo brasileiro, analfabetismo.

\section{ABSTRACT}

This article identifies some of the tensions and ambiguities present in the narrative of João Guimarães Rosa's Grande Sertão: Veredas. It analyses the protagonist Riobaldo Tatarana's process of insertion into the world of the hinterland hired bullies, inquiring into how the character embodies some of the crucial dilemmas of a republican political culture constitution in Brazil, especially as for the contradictions of the role of school in the Brazilian civic community formation of memoir and traditions. Moreover, this article postulate that the character Riobaldo Tatarana embodies into the narrative one of the most conflits in the constitution of a Brazilian republican political culture during the twentieth century, that of the relationships between culture of letters and the illiteracy.

Keywords: Political culture, Brazilian republicanism, illiteracy.

Recebido em abril de 2007 e aprovado em novembro de 2007 